\title{
Historical perspectives of The American Association for Thoracic Surgery: Bruce W. Lytle, MD
}

\author{
Stephen W. Davies, MD, MPH, Benjamin A. Hirsch, MD, and Christine L. Lau, MD, for the AATS \\ Centennial Committee
}

\footnotetext{
From the Division of Thoracic and Cardiovascular Surgery, University of Virginia Health System, Charlottesville, Va.

Disclosures: Authors have nothing to disclose with regard to commercial support. Received for publication May 27, 2016; accepted for publication June 17, 2016.

Address for reprints: Stephen W. Davies, MD, MPH, Division of Thoracic and Cardiovascular Surgery, University of Virginia Health System, PO Box 800679, Charlottesville, VA 22908 (E-mail: sd2wf@ hscmail.mcc.virginia. edu).

J Thorac Cardiovasc Surg 2016;152:651-4

$0022-5223 / \$ 36.00$

Copyright $(2016$ by The American Association for Thoracic Surgery

http://dx.doi.org/10.1016/j.jtcvs.2016.06.020
}

Pinned beneath 826 pounds of Screamin' Eagle, scorchin' blue-hot, American Steel on a remote but inviting stretch of serpentine highway in the middle of Nowheresville, Ohio, USA, alone-oh, and did we mention with a broken leg-is not an ideal scenario for even the most learned of motorcycle riders (B. Lytle, personal communication, April 2016). Well, this is where Dr Lytle found himself during the first sunny afternoon after a long, snowy winter.

Bruce W. Lytle (Figure 1) was born on September 10, 1945, in Minneapolis, Minn, to Dr and Mrs Francis Lytle. Lytle's father, a Navy veteran and medical internist, after returning home from World War II, moved the family to Fargo, ND, an area previously homesteaded by Lytle's grandfather in the 1920s. Dr Lytle recalls accompanying his father on many house calls while growing up. "I can remember how my father interacted with his patients . . . he was always very kind . . . he knew how to help people that were truly sick ... he was a real doctor . . many people said that about him" (B. Lytle, personal communication, April 2016). These memories would stay with Lytle and eventually inspire him to pursue a career in medicine.

Lytle attended Fargo Central High School, the first public high school in Fargo, ND, and the largest high school in the state. In high school, Lytle was an all-around athlete, playing football, basketball, track, and baseball; however, interestingly, he was not a straight-A student. "Between sports, state championships, hunting, fishing, and eventually girls, there just wasn't enough time" (B. Lytle, personal communication, April 2016). That being said, his peers would frequently comment that he was destined for something bigger than Fargo, ND. "It was almost expected or understood that I would go to a great school," Dr Lytle notes (B. Lytle, personal communication, April 2016), and after crushing the Scholastic Aptitude Test, he had his pick. When it came time to decide between East and West Coast schools, the decision was easy. He had never been to either, but "the West Coast just seemed more laid back; I felt like it would be a better fit" (B. Lytle, personal communication, April 2016).

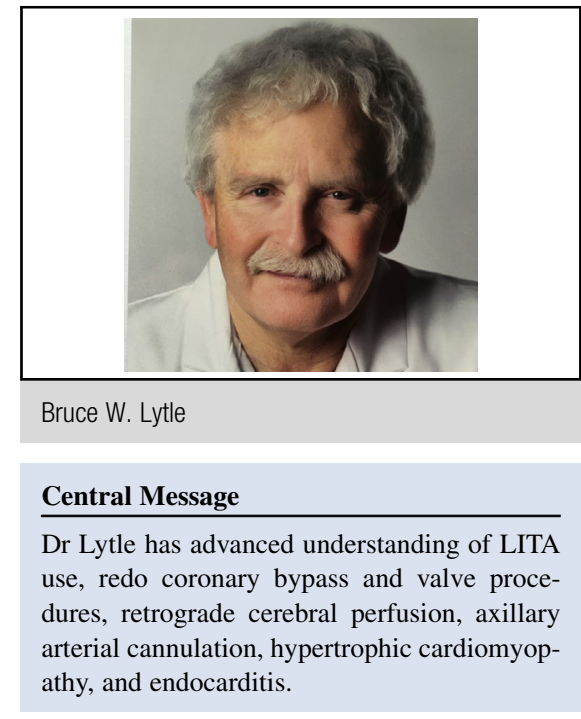

Lytle's interests in warmer climates led him to Standard University, in Palo Alto, Calif, in 1963 to pursue a degree in history. Driven by a strong awareness of work ethic and responsibility imparted by his father, he excelled early on both in the classroom and on the athletic field. He played football his first year and baseball his first 3 years as a walk on, yet

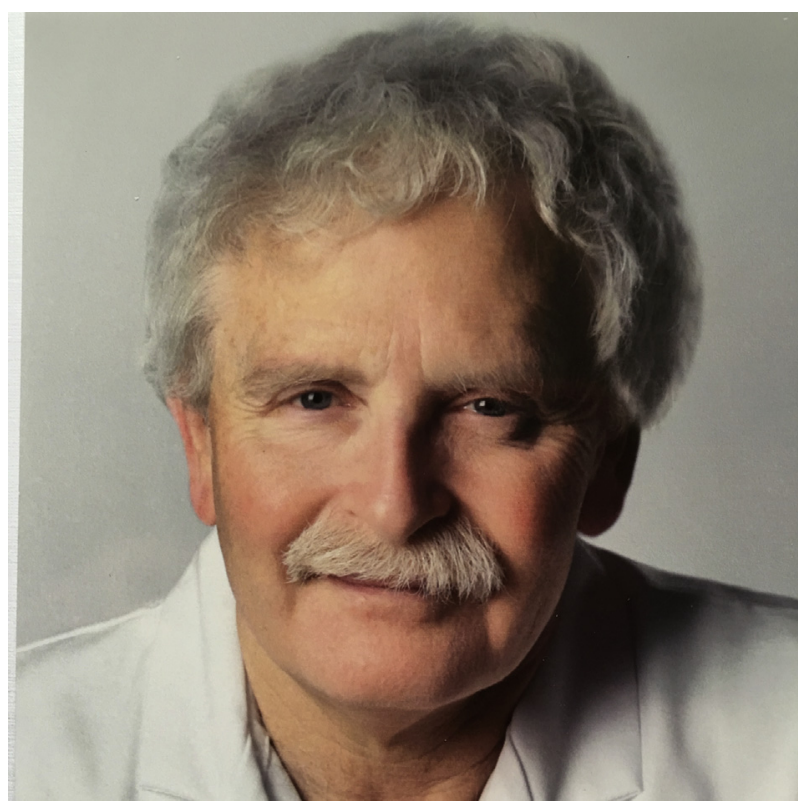

FIGURE 1. Dr Bruce W. Lytle. 
he simultaneously managed to maintain a recurrent presence on the Dean's List. During his first 2 years, Lytle considered obtaining his $\mathrm{PhD}$; however, he was not sure whether he would be able to write well enough to make a significant impact. Reminded of the time spent accompanying his father on house call visits, Lytle changed majors and ultimately graduated in 1967 with a Bachelor of Arts and Great Distinction in biology and premedical studies. Before graduating, Lytle asked his academic advisor, "Where's the best place to go for medical training" to which his advisor responded, "Well, if you can get into Harvard, I guess you should probably go" (B. Lytle, personal communication, April 2016). "At every fork in the road," Dr Lytle states, "I just always tried to do the best thing . . . nothing was ever mapped out in advance though" (B. Lytle, personal communication, April 2016).

Harvard's medical school curriculum, at that time, emphasized early clinical exposure. One of Lytle's first clinical experiences was on Dr Francis Daniels Moore's surgical service at Brigham and Women's Hospital. Dr Moore was credited with pioneering numerous experimental surgical treatments, including the management of critically ill surgical and burn patients, the first successful kidney transplant, and understanding how the volumes of water and other nutrients in the human body were affected during surgery. ${ }^{1}$ During the rotation, Dr Lytle remembers being queried on 3 specific surgical cases, "(1) a female with pancreatic carcinoma, (2) a trauma victim with a stab wound to the back, and (3) a female child run over by a water boat who had experienced significant soft tissue injury and fluid shifts." Dr Lytle recalls, "From then on, I was hooked. I knew that I should be involved in that kind of work ... problem solving, with immediate results and impact" (B. Lytle, personal communication, April 2016). It was also during this time that cardiothoracic surgery was significantly being advanced by such giants as Drs Robert Goetz and Michael Rohman (first coronary bypass operation in 1960), Dr Vasillii Kolesov (first planned and successful coronary bypass operation without cardiopulmonary bypass in 1964), Dr Rene Favaloro (helping to establish and popularize the coronary bypass operation in 1967), and Dr Christiaan Barnard (first human-to-human heart transplant in 1967). ${ }^{2,3}$ Dr Lytle reminisces, "The world was captivated . . . it was only natural that I became drawn to it ... it was very mechanistic . . . and I could make sense of it" (B. Lytle, personal communication, April 2016). Lytle graduated Cum Laude from Harvard Medical School in 1971.

"I knew I wanted to go to the best surgical residency training program after graduating medical school," notes Dr Lytle, "and everyone knew that Massachusetts General Hospital (MGH) was a great place to be for both general and cardiothoracic surgery" (B. Lytle, personal communication, April 2016). During his intern year, however, Lytle rotated primarily on general surgery rotations and participated in a wide variety of cases; it was not until his first year of residency that he was exposed to cardiothoracic

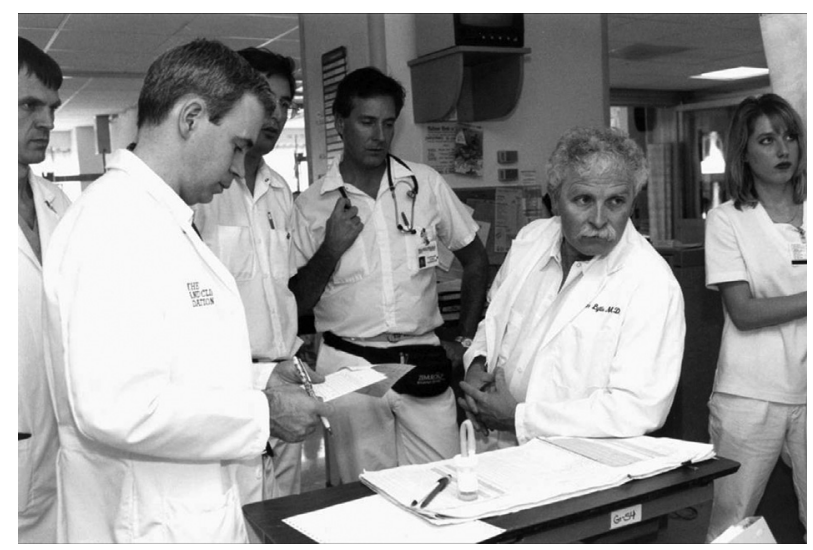

FIGURE 2. Teaching rounds with Dr Lytle.

surgery while rotating on Dr Mortimer Buckley's service. Dr Buckley was an absolute legend and helped pioneer myocardial revascularization, intra-aortic balloon pumps, the surgical treatment of cardiogenic shock and mechanical complications of acute myocardial infarction, and the technique of deep hypothermia and hemodilution for the correction of congenital anomalies. ${ }^{4}$ While many residents were intimidated by his teaching methods, Lytle thrived. Owing partially to his competitive nature as an athlete, his innate leadership qualities as a football quarterback and team captain, and the principles bestowed on him by his father, Lytle was intrigued. "Heart surgery was $90 \%$ routine, but $10 \%$ hard, and sometimes really hard ... I enjoyed the challenge ... I didn't shy away from that"' (B. Lytle, personal communication, April 2016). Lytle quickly found a routine place in Dr Buckley's operating room, and he had already performed many valve operations as the operating surgeon by the time he was a senior resident. After his fourth year in general surgery, Lytle traveled to London, England, to serve as senior registrar in cardiothoracic surgery at the Shotley Bridge Hospital. At 29 years of age, he was the lead surgeon, operating with an assistant on a wide variety of cardiac and thoracic cases alike. Interestingly, this happened to coincide with Newcastle's booming shipbuilding era and concomitant rises in diagnoses of lung disease, asbestos, and mesothelioma, so business was steady. After completing his general surgery training in 1977, Lytle remained at MGH to complete his residency in thoracic surgery, ultimately graduating to the position of chief resident of cardiovascular surgery in 1978. Two of Lytle's mentors during this time, Dr Buckley and Dr Cary Atkins (coresident) left lasting impressions that still resonate with Lytle to this day. "This was a period during the late 70 s when $10 \%$ of cardiothoracic surgery patients died . . . they were quite sick ... it gets your attention. Dr Buckley was exceptionally good at performing operations that people survived and conversely at avoiding operations that people would not. He was very cautious, but very calm and always in control. Dr Atkins was a very gifted surgeon ... he was always 


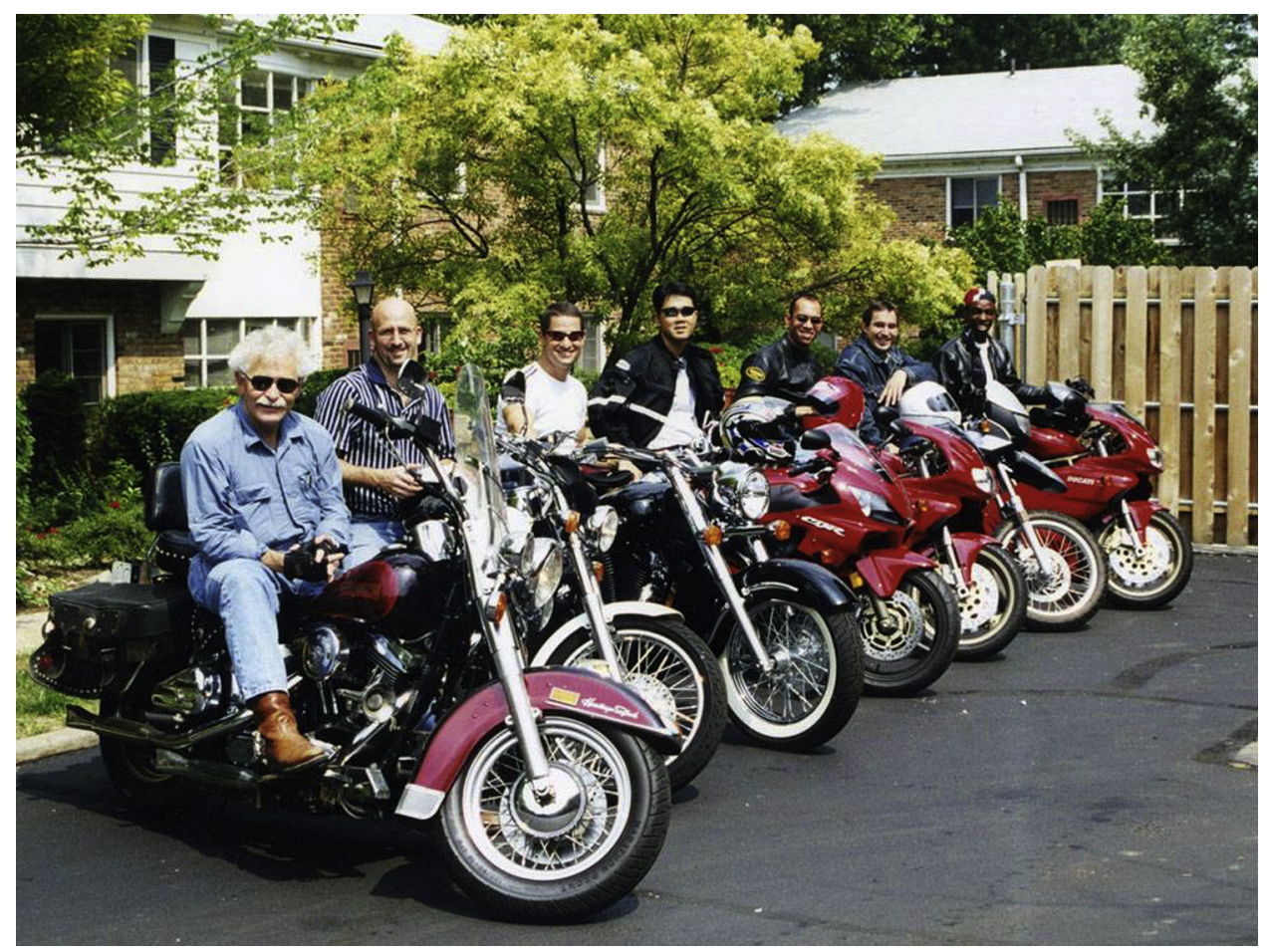

FIGURE 3. Dr Lytle and friends.

thoroughly prepared for each case ... he had thought about things well in advance ... he was very technically precise" (B. Lytle, personal communication, April 2016). During his time at MGH, Lytle developed lifelong friends who later became esteemed colleagues and leaders in cardiothoracic surgery: Robert Guyton, Doug Mathisen, and James Kirklin, to name a few.

After completing his training at MGH, Lytle was offered a position by Dr Floyd Loop as staff surgeon at the Cleveland Clinic in 1978. His colleague Dr Toby Cosgrove had been hired there 3 years previously and had recommended it. A fellow college baseball player who then played shortstop for the Cleveland Indians had also recommended Cleveland, Ohio, to him as a place to live. "It was something to do while waiting out the draft as the Vietnam War wound down ... it would help me be great ... it was an opportunity to be busy" (B. Lytle, personal communication, April 2016). During the introduction of Lytle at The American Association for Thoracic Surgery (AATS) meeting in 2007, Dr Craig Miller recalled, "There were no contracts at the Cleveland Clinic in those days, but as long as you did whatever Dr Loop said, then you got to keep your job." ${ }^{, 5}$ Lytle remained at the clinic for more than 35 years. During this time, he was elected to the Board of Governors from 1992 through 1996. He became the chair of the Department of Thoracic and Cardiovascular Surgery in 2004 and the chair of the Sydell and Arnold Miller Family Heart and Vascular Institute in 2007, a position that he would hold until 2014.
During Lytle's residency, there was never a push toward basic research. "Some people did it, but the emphasis was on being a reliable and dependable resident in the clinical care of patients. Plus, as a resident I was on call every other night, and every night as a senior resident" (B. Lytle, personal communication, April 2016). Then along came Dr Loop. "Dr Loop made it very clear that he wanted me to write," Lytle notes (B. Lytle, personal communication, April 2016). In his tenure at the Cleveland Clinic, Lytle was a part of what Norman Shumway called "the intellectual horsepower of cardiac surgery." Dr Steve Nissen, the chair of the Department of Cardiovascular Medicine at Cleveland Clinic, described Lytle as one of the finest physicians he has ever known and as a passionate advocate for quality of care and a visionary leader. ${ }^{6}$ During Lytle's presidential address at the AATS conference in 2007, he emphasized the important role that cardiothoracic surgeons must play in the ongoing evolution of cardiovascular care and treatment modalities, noting that the future of cardiac surgery and the care of cardiovascular patients will hinge on the ongoing ability of cardiac surgeons to innovate and cooperate with other members of the cardiovascular team and industry and that this is crucial for heart surgeons to remain at the forefront of care. ${ }^{7}$ Dr Lytle's commitment to the cardiac surgical literature is evidenced by a careerlong commitment to writing articles and contributing to the global knowledge base of the cardiac surgical world. To date, Lytle has published well over 400 articles and has advanced our understanding of the use of the left 


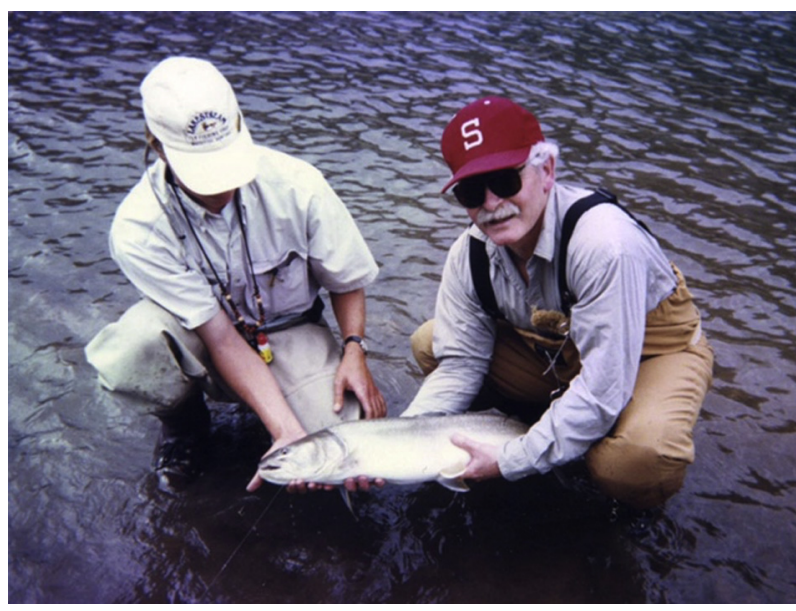

FIGURE 4. Dr Lytle fishing.

internal thoracic artery in coronary bypass surgery, reoperations on redo coronary bypass and redo valve procedures, retrograde cerebral perfusion for patients with bad atherosclerosis, axillary arterial cannulation, hypertrophic cardiomyopathy, and operations involving endocarditis. For these contributions, he was awarded the Dana A. Hamel Chair for Heart Disease Research in 2006.

The concluding remarks of Dr Lytle's AATS presidential address are as follows: "We share much that is truly inspiring. Only we know the joy of what it is to be able to go into the operating room, to hold in your hands a damaged heart, and to be able to reconstruct it to allow someone a long life, and more happiness. Cardiac surgery has provided our lives with a great purpose and with a profound meaning. We owe a great deal for this." belief in mentoring and education. Dr Lytle understands and emphasizes that most cardiac surgeons went into the field because of passion and because they love it. He states that "you do cardiac surgery with your heart" ${ }^{17}$ rather than logic. He does believe that an evolution in the training of cardiac surgeons is important to continue to bring new surgeons into the field. And he believes that the future of cardiac surgery rests on finding "the eagles,", those who will enter the field and be leaders. His dedication to teaching residents and fellows earned him the 2004 Thoracic Surgery Residents Association Socrates Teaching Award (Figure 2).

Dr Lytle holds many memberships, including the AATS (serving as president in 2006-2007), the American College of Surgeons, the American College of Cardiology, the American Heart Association, the American Medical Association, the Ohio Chapter of the American College of Surgeons, the Ohio State Medical Association, the Cleveland Academy of Medicine, the Society of Thoracic Surgeons, and the American Surgical Association. Despite his tireless commitment to surgery and surgical education, he still

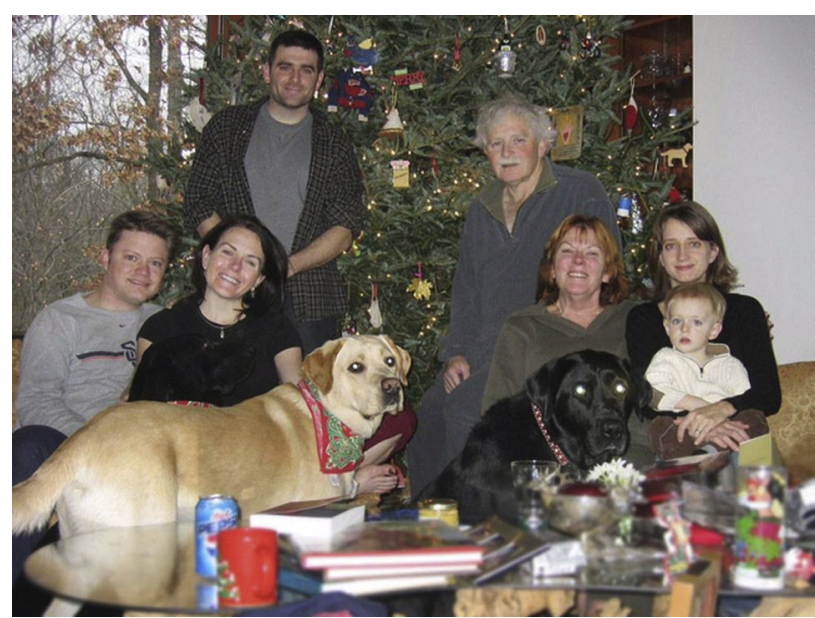

FIGURE 5. Dr Lytle and family.

makes time for his hobbies, which include, most notably, riding Harley-Davidson motorcycles with his friends (Figure 3) and frequenting the annual rally in Sturgis, SD. $\mathrm{He}$ is also an avid outdoorsman who enjoys hunting as well as fishing (Figure 4) with the same high school friends from Fargo, ND. Dr Lytle's family is a central anchor in his life and includes his wife, Suzanne Baker, whom he married during his training years; his son, Ted, who is an intensivist at Case Western; his daughter, Madora, who is an attorney in Boston; and his 5 grandchildren (Figure 5).

To return to the scene at the beginning of this profile, after weighing his options, Lytle recalled some sage and opportune advice from a former patient of his (B. Lytle, personal communication, April 2016). He turned his back to the bike, squatted down, and simultaneously lifted the HarleyDavidson Road King while trying to support his broken leg. He then brushed the dirt off and rode home. "In the end, I'm just a guy who gets up and tries to help people out. There will be good days and bad days, but its important to come back tomorrow and try it again. It's been a wonderful life and profession, and I would do it all over again if given the opportunity."

\section{References}

1. Brennan MF. Francis Daniels Moore. Surgery. 2003;133:112-3.

2. Chaikhouni A. The magnificent century of cardiothoracic surgery. Heart Views. 2010;11:31-7.

3. Cooper DK. Christiaan Barnard and his contributions to heart transplantation. $J$ Heart Lung Transplant. 2001;20:599-610.

4. Wright CD, Akins CW. Historical perspectives of The American Association for Thoracic Surgery: Mortimer J. Buckley (1932-2007). J Thorac Cardiovasc Surg. 2013;146:6-8.

5. Miller C. Introduction of Bruce Lytle. Presented at: 87th Annual Meeting of The American Association for Thoracic Surgery; May 7, 2007; Washington, DC.

6. O'Riordan M. Dr Bruce Lytle named chair of the Cleveland Clinic's Heart and Vascular Institute. Heartwire from Medscape. October 5, 2007. Available at: http://www.medscape.com.

7. Lytle B. Who we are-who we will be. J Thorac Cardiovasc Surg. 2008;135: 965-75. 